Review

\title{
Association between the APEX1 Asp148Glu polymorphism and prostate cancer, especially among Asians: a new evidence- based analysis
}

\author{
Yang Chen ${ }^{1,2,4, *}$, Jie $\mathbf{L i}^{1,3, *}$ and Zengnan $\mathrm{Mo}^{1,2,4}$ \\ ${ }^{1}$ Center for Genomic and Personalized Medicine, Guangxi Medical University, Nanning, Guangxi Zhuang Autonomous Region, \\ China \\ 2 Department of Urology and Nephrology, The First Affiliated Hospital of Guangxi Medical University, Nanning, China \\ ${ }^{3}$ Research Center for Guangxi Reproductive Medicine, First Affiliated Hospital of Guangxi Medical University, Guangxi Zhuang \\ Autonomous Region, China \\ ${ }^{4}$ Guangxi Key Laboratory for Genomic and Personalized Medicine, Guangxi Collaborative Innovation Center for Genomic and \\ Personalized Medicine, Nanning, Guangxi Zhuang Autonomous Region, China \\ * These authors have contributed equally to this work \\ Correspondence to: Zengnan Mo, email: zengnanmo@hotmail.com
}

Keywords: APEX1, rs 1130409 , polymorphism, prostate cancer

Received: November 22, $2015 \quad$ Accepted: May 16, 2016

Published: May 29, 2016

\section{ABSTRACT}

Background: Prostate cancer (Pca) is a serious disease associated with considerable morbidity and mortality. As a causative factor, the Asp148Glu polymorphism has been identified in the apurinic/apyrimidinic endonuclease (APEX1) gene. However, the association among Asians is considered controversial.

Methods: Evidence for this association was obtained from the PubMed, Embase, HuGENet and Chinese National Knowledge Infrastructure (CNKI) databases. In the analysis, four models were applied. Associations between the APEX1 polymorphism and the invasiveness of Pca based on the Gleason score, prostate-specific antigen expression and clinical status were also evaluated.

Results: Seven articles were included in the analysis. Positive results were not only discovered in the pooled analysis, but also among patients of mixed descent and Asian descent . However, after considering the Hardy-Weinberg equilibrium (HWE), we observed only a 1.557-fold increase in Pca risk for subjects of Asian descent (GG vs. $\mathrm{TT}$ : $\mathrm{OR}=1.557,95 \% \mathrm{CI}=1.069-2.268$ ) under the co-dominant model. Additionally, we did not also find any relationship between the APEX1 Asp148Glu polymorphism and invasive Pca risk.

Conclusion: On the basis of the function of the APEX1 Asp148Glu polymorphism, recent studies, and our results, we suggest that the APEX1 Asp148Glu polymorphism might be important in stimulating the development of Pca rather than its invasiveness in various populations, especially for Asians.

\section{INTRODUCTION}

Prostate cancer (Pca) was one of the mostly frequently diagnosed malignant diseases worldwide. It is associated with considerable morbidity and is the second leading cause of cancer mortality in western countries [1-3]. In 2016, an estimated 180,890 new cases of Pca and 26,120 deaths are projected to occur in the United States [4]. Moreover, the incidence of Pca in China has been increasing [5]. As a multi-factorial disease, many factors are known to play a key role in Pca development, such as age, ethnicity, diet, and geographic factors [6]. Recently, hereditary factors have also been identified to be significantly associated with Pca [7], particularly regarding polymorphisms in the apurinic/apyrimidinic endonuclease (APEX1) gene [8].

The APEX1 gene is located on chromosome 14 from 20455131 bp to 20457772 bp. It encodes for an enzyme belonging to the base excision repair (BER) pathway, which is important in the repair of DNA damage caused by 
Table 1: the essential characteristics of the eligible studies included in this analysis

\begin{tabular}{|c|c|c|c|c|c|c|c|c|c|c|c|c|}
\hline Author & Years & Country & Race & Case & Control & Method & caseG & caseT & controlG & controlT & N.case & N.control \\
\hline $\begin{array}{l}\text { Pournourali } \\
\text { M et al }\end{array}$ & 2015 & Iran & Asian & Pca & $\begin{array}{l}\text { disease-free control } \\
\text { subjects }\end{array}$ & PCR-RFLP & 110 & 90 & 90 & 110 & 100 & 100 \\
\hline Jing B et al & 2013 & China & Asian & $\begin{array}{l}\text { Pca confirmed by } \\
\text { histopathological } \\
\text { examination }\end{array}$ & $\begin{array}{l}\text { without cancers } \\
\text { matched to the case } \\
\text { group by age, diet or } \\
\text { life style }\end{array}$ & PCR-RFLP & 166 & 230 & 119 & 193 & 198 & 156 \\
\hline $\begin{array}{l}\text { Mandal RK } \\
\text { et al }\end{array}$ & 2012 & India & Asian & $\begin{array}{l}\text { histologic presence of } \\
\text { adenocarcinoma of the } \\
\text { prostate in the biopsy } \\
\text { specimen }\end{array}$ & $\begin{array}{l}\text { cancer free, unrelated, } \\
\text { age matched healthy } \\
\text { control individuals of } \\
\text { similar ethnicity }\end{array}$ & ARMS-PCR & 101 & 283 & 118 & 330 & 192 & 224 \\
\hline $\begin{array}{l}\text { Mittal RD } \\
\text { et al }\end{array}$ & 2012 & India & Asian & $\begin{array}{l}\text { histologically } \\
\text { confirmed Pca }\end{array}$ & $\begin{array}{l}\text { cancer free, unrelated, } \\
\text { age and sex matched } \\
\text { healthy individuals of } \\
\text { similar ethnicity }\end{array}$ & ARMS-PCR & 102 & 288 & 127 & 373 & 195 & 250 \\
\hline $\begin{array}{ll}\text { Kuasne } & \mathrm{H} \\
\text { et al } & \end{array}$ & 2011 & Brazil & Mix & $\begin{array}{l}\text { suspicious findings } \\
\text { on a digital rectal } \\
\text { examination (DRE) } \\
\text { and/or elevated PSA } \\
\text { serum levels (C2.5 } \\
\text { ng/ml), followed by } \\
\text { histopathological } \\
\text { confirmation } \\
\text { prostate cancer }\end{array}$ & $\begin{array}{l}\text { cancer-free men with } \\
\text { negative DRE and } \\
\text { serum levels of PSA } \\
\text { levels lower than } 2 \text { ng/ } \\
\text { ml, matched to cancer } \\
\text { patients on the basis } \\
\text { of age ( } \pm 5 \text { years), } \\
\text { ethnic group (Euro and } \\
\text { African descendents), } \\
\text { and drinking and } \\
\text { smoking habits }\end{array}$ & PCR-RFLP & 93 & 251 & 68 & 276 & 172 & 172 \\
\hline $\begin{array}{l}\text { Lavender } \\
\text { NA et al }\end{array}$ & 2010 & America & African & $\begin{array}{l}\text { histological } \\
\text { confirmation of Pca }\end{array}$ & healthy volunteers & TaqMan-PCR & 120 & 252 & 445 & 817 & 186 & 631 \\
\hline Chen $\mathrm{L}$ et al & 2006 & America & Mix & $\begin{array}{l}\text { primary } \\
\text { adenocarcinoma of the } \\
\text { prostate }\end{array}$ & without cancers & PCR-RFLP & 302 & 400 & 261 & 397 & 351 & 329 \\
\hline
\end{tabular}

* Pca: prostate cancer; PCR: Polymerase Chain Reaction; PCR-RFLP: polymerase chain reaction-restriction fragment length polymorphism; ARMS: amplification refractory mutation specific; N.case: the total number of cases; N.control: the total number of controls.

* Kuasne $\mathrm{H}$ et al. : Mix descent included European and African descents.

* Chen L et al. : Mix descent included 240 black (which could be classified into African descent) and 447 white (which could be classified into Mix descent or Caucasians)

* Lavender et al. : African descent included African-Americans, West Africans, East Africans and Caribbeans

oxidative reagents and alkylation [9-10]. As one of the key genes in the BER pathway, APEX1 identifies and splits phosphodiester bonds via a hydrolytic mechanism on the 5 '-side of abasic sites, thus specifically activating DNA repair [11]. This gene also participates in other crucial cellular processes, such as the response to oxidative stress, cell cycle control, and apoptosis [12]. In 2013, Pan et al. [13] suggested that the APEX1 gene might be one of risk factors contributing to the morbidity of lung cancer. In addition, other diseases, such as cervical cancer [14], ovarian cancer [15], and colorectal cancer [16] have also been associated with APEX1 gene polymorphisms.

There are several polymorphisms in the APEX1 gene, of which Asp148Glu (rs1130409) has been associated with many cancers [14-16, 23-25, 27] . In 2001, Hu et al. [33] conducted a study on the association between variants of APE1 and ionizing radiation, which suggested that the $\mathrm{G}$ allele transformed from $\mathrm{T}$ (Asp $>$ Glu) is associated with mitotic delay in lymphocytes, providing greater sensitivity to ionizing radiation. Moreover, the $\mathrm{G}$ of allele rs 1130409 was also found to increase the risk for the development of Pca [17, 22]. On the basis of the function of the APEX1 gene, it has been speculated that the $\mathrm{G}$ allele of the APEX1 Asp148Glu polymorphism might have an effect on normal DNA repair, and may play a role in inducing Pca. However, this association was considered controversial in follow-up studies [8], especially among Asians. In order to evaluate the real association, the latest and most convincing evidence was used in this meta-analysis.

\section{RESULTS}

\section{Characteristics of the retrieval and eligible studies}

In the retrieval, four databases (PubMed, HuGENet, Embase and CNKI) were searched by combining the key words. Finally, 478 studies were included. When screening these studies by reading all the abstracts, 34 repeated studies in four databases were removed. Meanwhile, 437 studies were also excluded as there was no evidence of studying the association between Pca risk and APEX1 gene polymorphisms. Then, only seven studies were left. However, while scanning all the full texts, one study written by Agalliu et al. in 2010 was removed, as it was mainly focused on the association between the other APEX1 gene polymorphisms (rs1320150 and rs2275007) and Pca [19]. Moreover, by reading the references in the related studies carefully, one additional study was also found to be eligible [29]. Thus, seven articles with intact genotype data were included in the whole analysis $[8,17$, 
Table 2: Results after meta-analysis with dominant model (GG+GT vs TT), recessive model (GG vs GT+TT), codominant model (GG vs GT; GG vs TT) and per-allele analysis (G vs T) involved

\begin{tabular}{|c|c|c|c|c|c|c|c|}
\hline Subgroups & Model & OR & $95 \% \mathrm{CI}$ & I2 & $\mathbf{P}$ & Statistical Power & Authors \\
\hline Asian Descent & Dominant model (GG+GT vs TT) & 1.106 & $0.891,1.374$ & $55.90 \%$ & 0.079 & $32.70 \%$ & $\begin{array}{l}\text { Pournourali etal., Jing et al., Mandal et al., } \\
\text { Mittal et al. }\end{array}$ \\
\hline Asian Descent & Recessive model (GG vs GT+TT) & 1.347 & $0.957,1.895$ & $0.00 \%$ & 0.956 & $59.90 \%$ & \\
\hline Asian Descent & Codominant model (GG vs GT) & 1.266 & $0.885,1.811$ & $0.00 \%$ & 0.736 & $7.60 \%$ & \\
\hline Asian Descent & Codominant model (GG vs TT) & 1.557 & $1.069,2.268$ & $0.00 \%$ & 0.684 & $65.90 \%$ & \\
\hline Asian Descent & Per-allele analysis (G vs T) & 1.130 & $0.962,1.326$ & $0.00 \%$ & 0.41 & $59.70 \%$ & \\
\hline Mix Descent & Dominant model (GG+GT vs TT) & 1.450 & $1.081,1.943$ & $0.00 \%$ & 0.35 & $70.90 \%$ & Kuasne et al., Chen et al. \\
\hline Mix Descent & Recessive model (GG vs GT + TT) & 1.189 & $0.744,1.900$ & $0.00 \%$ & 0.342 & $12.10 \%$ & \\
\hline Mix Descent & Codominant model (GG vs GT) & 1.073 & $0.656,1.753$ & $0.00 \%$ & 0.468 & $5.00 \%$ & \\
\hline Mix Descent & Codominant model (GG vs TT) & 1.415 & $0.837,2.393$ & $1.70 \%$ & 0.313 & $33.30 \%$ & \\
\hline Mix Descent & Per-allele analysis (G vs T) & 1.261 & $1.019,1.559$ & $32.00 \%$ & 0.225 & $58.40 \%$ & \\
\hline African Descent & Dominant model (GG+GT vs TT) & 1.021 & $0.771,1.352$ & $0.00 \%$ & 0.589 & $11.10 \%$ & Lavender et al., Chen et al. \\
\hline African Descent & Recessive model (GG vs GT+TT) & 0.771 & $0.495,1.200$ & $71.10 \%$ & 0.063 & $21.90 \%$ & \\
\hline African Descent & Codominant model (GG vs GT) & 0.745 & $0.468,1.183$ & $69.40 \%$ & 0.071 & $32.00 \%$ & \\
\hline African Descent & Codominant model (GG vs TT) & 0.803 & $0.501,1.287$ & $67.10 \%$ & 0.081 & $11.00 \%$ & \\
\hline African Descent & Per-allele analysis (G vs T) & 0.954 & $0.778,1.171$ & $38.30 \%$ & 0.203 & $5.00 \%$ & \\
\hline All & Dominant model (GG+GT vs TT) & 1.159 & $1.000,1.344$ & $37.40 \%$ & 0.131 & $70.90 \%$ & \multirow{2}{*}{$\begin{array}{l}\text { Pournourali etal., Jing et al., Mandal et } \\
\text { al., Mittal et al., Kuasne et al., Chen et al., } \\
\text { Lavender et al }\end{array}$} \\
\hline All & Recessive model (GG vs GT+TT) & 1.112 & $0.882,1.401$ & $14.00 \%$ & 0.32 & $16.30 \%$ & \\
\hline All & Codominant model (GG vs GT) & 1.043 & $0.818,1.330$ & $11.70 \%$ & 0.339 & $5.30 \%$ & \\
\hline All & Codominant model (GG vs TT) & 1.246 & $0.968,1.605$ & $30.10 \%$ & 0.188 & $99.80 \%$ & \\
\hline All & Per-allele analysis (G vs T) & 1.108 & $0.995,1.235$ & $25.90 \%$ & 0.222 & $62.20 \%$ & \\
\hline
\end{tabular}

* Three subgroups were divided: Asian descent, Mix descent and African descent .

* $\mathrm{OR}=$ odd ratio; $\mathrm{CI}$ : confidence interval.

* The Statistical Power was calculated with the Power and Precision V4 software (http://www.power-analysis.com/).

Table 3: Association between APEX1 Asp148Glu polymorphism and three main indexes about the Pca development (GS, clinical status and PSA level)

\begin{tabular}{|c|c|c|c|c|c|c|c|}
\hline Index & Race & Model & OR & $95 \% \mathrm{CI}$ & 12 & $\mathbf{P}$ & \\
\hline GS & Asian Descent & Dominant model (GG+GT vs TT) & 1.169 & $0.745,1.834$ & $35.80 \%$ & 0.212 & Jing et al., Mandal et al. \\
\hline GS & Asian Descent & Recessive model (GG vs GT+TT) & 1.078 & $0.644,1.807$ & $31.70 \%$ & 0.226 & \\
\hline GS & Asian Descent & Codominant model (GG vs GT) & 0.898 & $0.265,3.049$ & $70.40 \%$ & 0.066 & \\
\hline GS & Asian Descent & Codominant model (GG vs TT) & 0.876 & $0.454,1.691$ & $0.00 \%$ & 0.704 & \\
\hline GS & Asian Descent & Per-allele analysis (G vs T) & 1.109 & $0.811,1.517$ & $0.00 \%$ & 0.784 & \\
\hline GS & Mix Descents & *Dominant model (GG+GT vs TT) & 1.164 & $0.811,1.669$ & $0.00 \%$ & 0.459 & Jing et al., Mandal et al., Kuasne et al. \\
\hline clinical status & Asian Descent & Dominant model $(\mathrm{GG}+\mathrm{GT}$ vs TT) & 1.06 & $0.303,3.712$ & $87.40 \%$ & 0.005 & Jing et al., Mandal et al. \\
\hline clinical status & Asian Descent & Recessive model (GG vs GT+TT) & 1.53 & $0.911,2.569$ & $0.00 \%$ & 0.593 & \\
\hline clinical status & Asian Descent & Codominant model (GG vs GT) & 1.335 & $0.737,2.418$ & $0.00 \%$ & 0.658 & \\
\hline clinical status & Asian Descent & Codominant model (GG vs TT) & 1.747 & $0.955,3.195$ & $40.60 \%$ & 0.194 & \\
\hline clinical status & Asian Descent & Per-allele analysis (G vs T) & 1.109 & $0.469,2.625$ & $86.30 \%$ & 0.007 & \\
\hline clinical status & Mix Descents & *Dominant model $(\mathrm{GG}+\mathrm{GT}$ vs TT) & 0.903 & $0.416,1.963$ & $78.30 \%$ & 0.01 & Jing et al., Mandal et al., Kuasne et al. \\
\hline PSA & Mix Descents & *Dominant model $(\mathrm{GG}+\mathrm{GT}$ vs TT) & 0.897 & $0.560,1.437$ & $0.00 \%$ & 0.62 & Jing et al., Kuasne et al. \\
\hline
\end{tabular}

* The results of "*Dominant model (GG+GT vs TT)" contained three sets of data (reference 8, 20, 22) with mix races.

* GS: Gleason score; PSA: prostate-specific antigen

* GS groups: the high vs. low Gleason score (Gleason $\geq 7$ versus Gleason $<7$ )

* Clinical status groups: case: Advanced or Metastasis (+) or clinical stages $\geq \mathrm{T} 3$; control: Localized or Metastasis (-) or clinical stages $<\mathrm{T} 3$

* PSA group modeled as a categorical variable. The threshold was 10ng/ml (PSA case: PSA $>10$ ng/mL, PSA control: PSA $\leq 10$ $\mathrm{ng} / \mathrm{mL}$ ) 


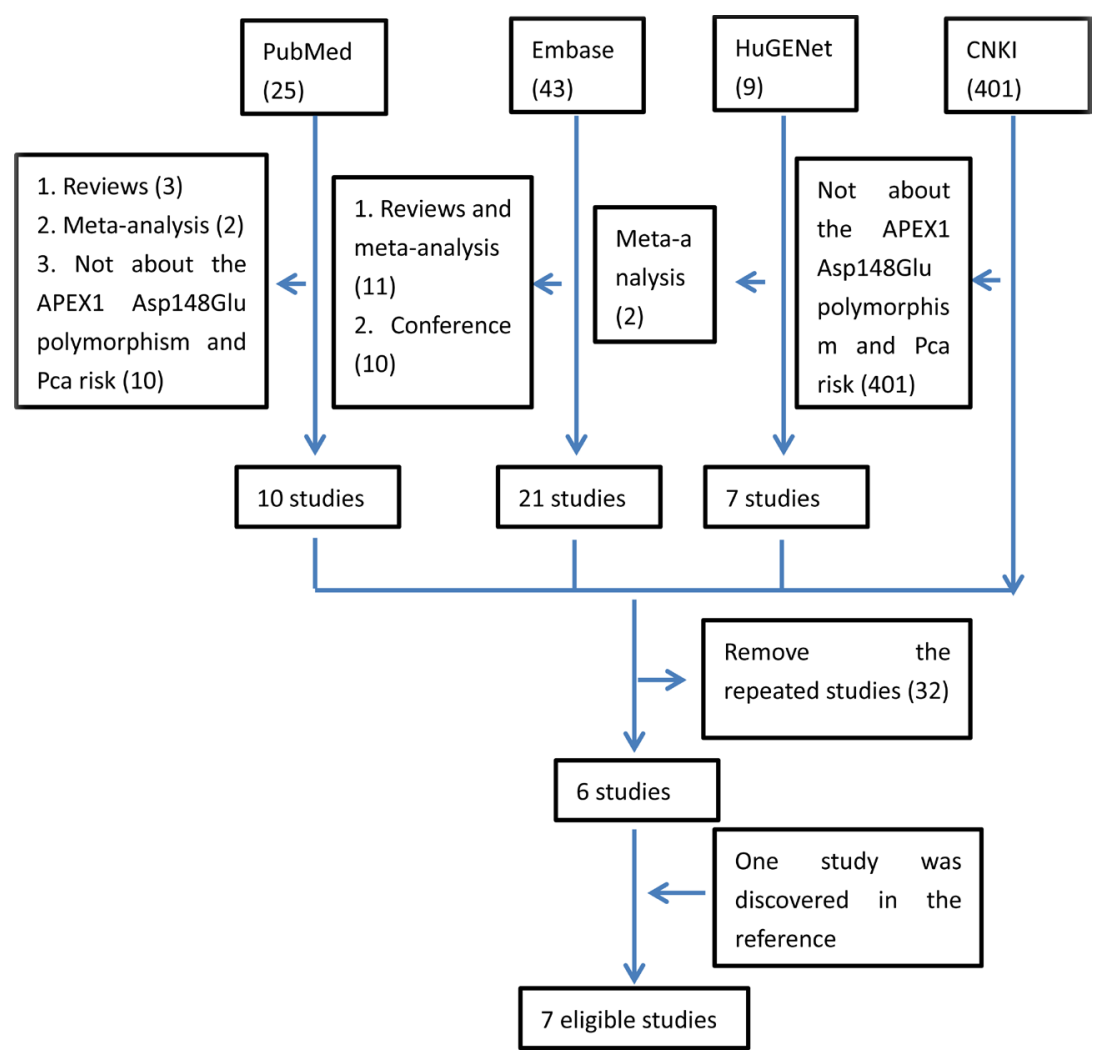

Figure 1: The flow of retrieval for this study.

Study

Asian

Pournourali M et al (Iran) (2015)

Jing B et al (Chinese) (2013)

Mandal RK et al (Indian) (2012)

Mittal RD et al (Indian) (2012)

Subtotal (I-squared $=55.9 \%, \mathbf{p}=0.079$ )

Mix

Kuasne H et al (Brazil, European \& African Descent) (2011)

Chen L et al (U.S., 447 White Descent) (2006)

Subtotal (I-squared $=0.0 \%, \mathrm{p}=0.350$ )

African

Lavender NA et al(African-Americans, West Africans, East Africans and Caribbean) (2010)

Chen L et al (U.S., 240 African Descent) (2006)

Subtotal (I-squared $=0.0 \%, \mathrm{p}=0.589$ )

Overall $(I-$ squared $=37.4 \%, p=0.131)$
$2.43(1.21,4.87) \quad 3.21$

$1.25(0.81,1.94) \quad 10.96$

$0.90(0.61,1.33) \quad 16.54$

$0.96(0.66,1.40) \quad 16.94$

$1.11(0.89,1.37) \quad 47.65$

$1.68(1.10,2.58) \quad 9.87$

$1.27(0.85,1.90) \quad 12.88$

$1.45(1.08,1.94) \quad 22.75$

$0.97(0.70,1.35) \quad 21.94$

$1.16(0.68,1.97) \quad 7.66$

$1.02(0.77,1.35) \quad 29.60$

$1.16(1.00,1.34) \quad 100.00$

Figure 2: Meta-analysis with fixed effects and dominant model (GG+GT $v s$ TT) for the association between APEX1 Asp148Glu polymorphism and the prostate cancer risk . The first author and year of publication for each study was shown. In this analysis, three subgroups were shown: Asian descent, African descent and Mix races. OR and accompanying $95 \% \mathrm{CI}$ were also presneted for this association. 
20-22, 29, 30]. The flow of retrieval was showed in Figure 1.

Among these eligible studies, most of the samples came from local medical institutions. Genomic DNA mainly came from the peripheral blood of the participants. Genotyping was conducted with polymerase chain reaction (PCR). Cases were defined as Pca patients who had been confirmed by histopathological examination. Cancer-free and healthy subjects were identified as the controls, who were matched to the cases by age or other characteristics. Among the eligible studies, three included subjects of Asian descent from China, Iran, and India [8, 20-21, 30]. Two from Brazil and America included subjects of mixed race, mostly European and African descent, and others involved $[17,22]$. The last study included subjects of African descent (including selfidentified African American, East African, West African, and Afro-Caribbean subjects) from America [29]. Among the eligible studies, samples in the Chen et al. [17] study could be divided into black (which could be classified into African descent) and white (which could be classified into mixed descent or Caucasian), in which the black subjects could be combined with the subjects of the Lavender et al. [29] study. So, in this analysis, three ethnic subgroups were defined as follows: Asian descent (Pournourali et al. [30], Jing et al. [8], Mandal et al. [20] and Mittal et al. [21]), African descent (Lavender et al. [29] and Chen et al. [17]) and mixed descent including European and African (Chen et al. [17] and Kuasne et al. [22]). After analysis, a significant association was discovered which had not been reported before.

\section{APEX1 Asp148Glu polymorphism associated with Pca}

In contrast to previous meta-analyses [31-32], this study discovered a significant relationship between the APEX1 Asp148Glu polymorphism and Pca risk in the pooled results (dominant model: $\mathrm{OR}=1.159,95 \% \mathrm{CI}=$ $1.000-1.344, I^{2}=37.40 \%$, statistical power $=70.90 \%$ ) (Figures 2-3, Table 2 ). In order to identify the possible association, a subgroup analysis was conducted. At this stage, the samples were divided into subjects of

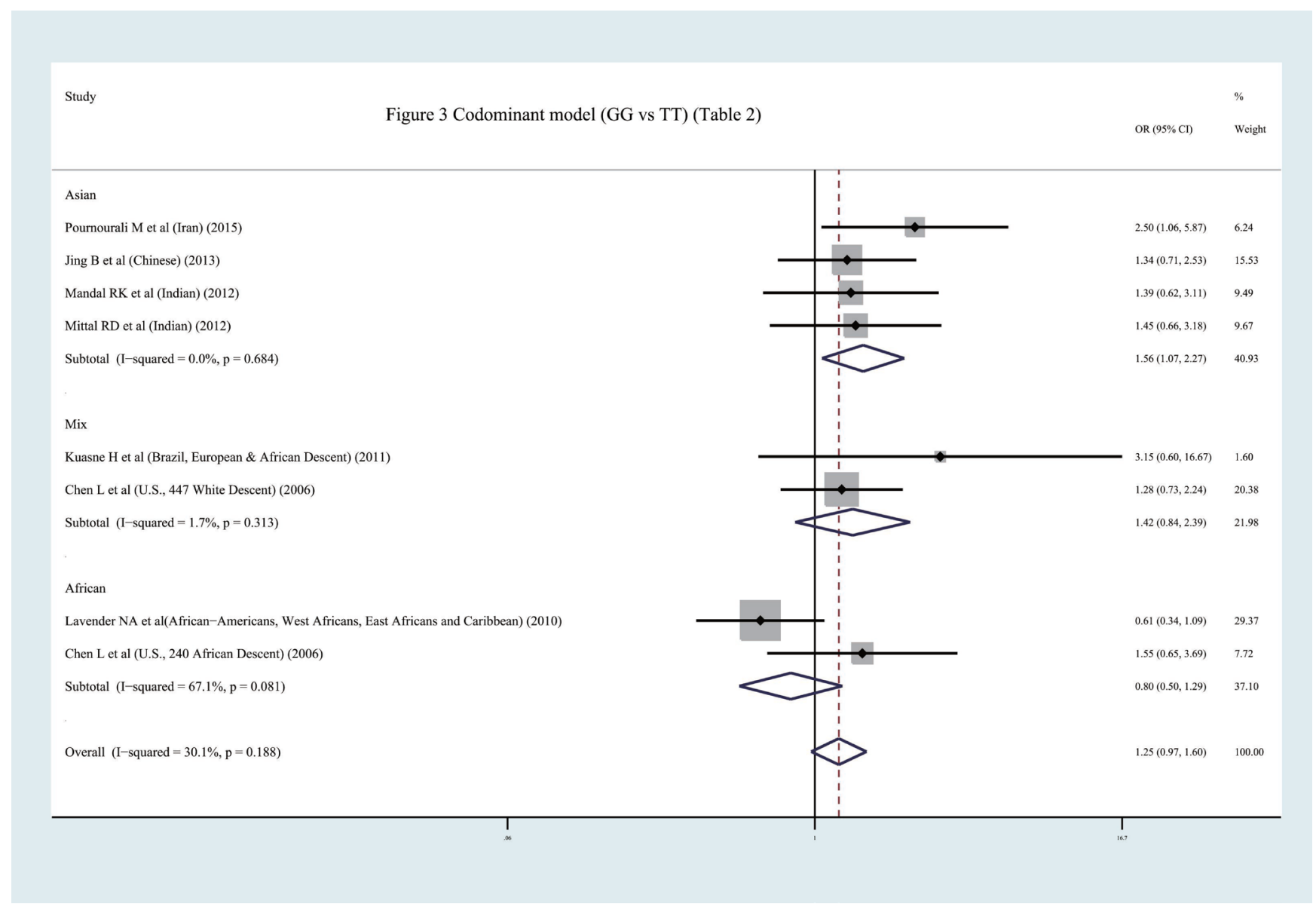

Figure 3: Meta-analysis with fixed effects and Codominant model (GG $v s$ TT) for the association between APEX1 Asp148Glu polymorphism and the prostate cancer risk. The first author and year of publication for each study was shown. In this analysis, three subgroups were shown: Asian descent, African Descent and Mix races. OR and accompanying 95\% CI were also presneted for this association. 
Asian descent, mixed descent and African descent . Although there were no positive results in the African group, our results suggested that the APEX1 Asp148Glu polymorphism was significantly related to Pca in the subjects of mixed descent (dominant model: $\mathrm{OR}=1.450$, $95 \% \mathrm{CI}=1.081-1.943, I^{2}=0.00 \%$; per-allele analysis : OR $=1.261,95 \% \mathrm{CI}=1.019-1.559, I^{2}=32.00 \%$ ), which had been demonstrated previously [32] (Figure 2, Table 2 ). Meanwhile, a potential association between the APEX1 Asp148Glu polymorphism and Pca risk among subjects of Asian descent was also discovered, which had not been reported before (co-dominant model (GG vs. TT): $\mathrm{OR}=1.557,95 \% \mathrm{CI}=1.069-2.268, I^{2}=0 \%$, statistical power $=65.90 \%)($ Figure 3, Table 2$)$. Next, the HardyWeinberg equilibrium (HWE) of each study was taken into consideration; one study did not satisfy HWE and was removed ( $P=0.0232)$ [22]. After re-analysis, the positive association disappeared among subjects of mixed descent and all pooled ethnic backgrounds. A publication bias for the co-dominant model (GG vs. TT) is shown in Figure 4 $(P=0.120)$, which further confirmed that the association among subjects of Asian descent was reliable to some extent.

\section{Sensitivity analysis}

In order to confirm the association between the APEX1 Asp148Glu polymorphism and Pca risk after considering the HWE, a sensitivity analysis was conducted by excluding each study one at a time individually for every genotype model. To our surprise, a positive association emerged again in the co-dominant model (GG vs. TT) (Asian descent: $\mathrm{OR}=1.557,95 \% \mathrm{CI}=1.069$ $2.268, I^{2}=0.0 \%$, statistical power $=65.90 \%$; pooled descent: $\mathrm{OR}=1.474,95 \% \mathrm{CI}=1.099-1.976, I^{2}=0.0 \%$; $P_{\text {for publication bias }}=0.150$, statistical power $\left.=9.40 \%\right)$ and the per-allele analysis (G vs. T) (pooled descent: $\mathrm{OR}=1.137$, $95 \% \mathrm{CI}=1.000-1.294, I^{2}=0.0 \% ; P_{\text {for publication bias }}=0.223$ , statistical power $=75.00 \%$ ) after removing the same study [29].

\section{Gleason score, prostate-specific antigen and clinical status}

In this part of the study, we tried to investigate the function of the APEX1 Asp148Glu polymorphism in the development of Pca, on the basis of the Gleason score, prostate-specific antigen expression and clinical status of the cancer. Three studies with related information were included $[8,20,22]$. Two of them included subjects of Asian descent $[8,20]$ and one included subjects of mixed descent with data on only the dominant modl (GG+GT vs. TT) [22]. After analysis, we did not observe any significant relationship between the APEX1 Asp148Glu polymorphism and Pca invasiveness (Figure 5, Table 3 ).

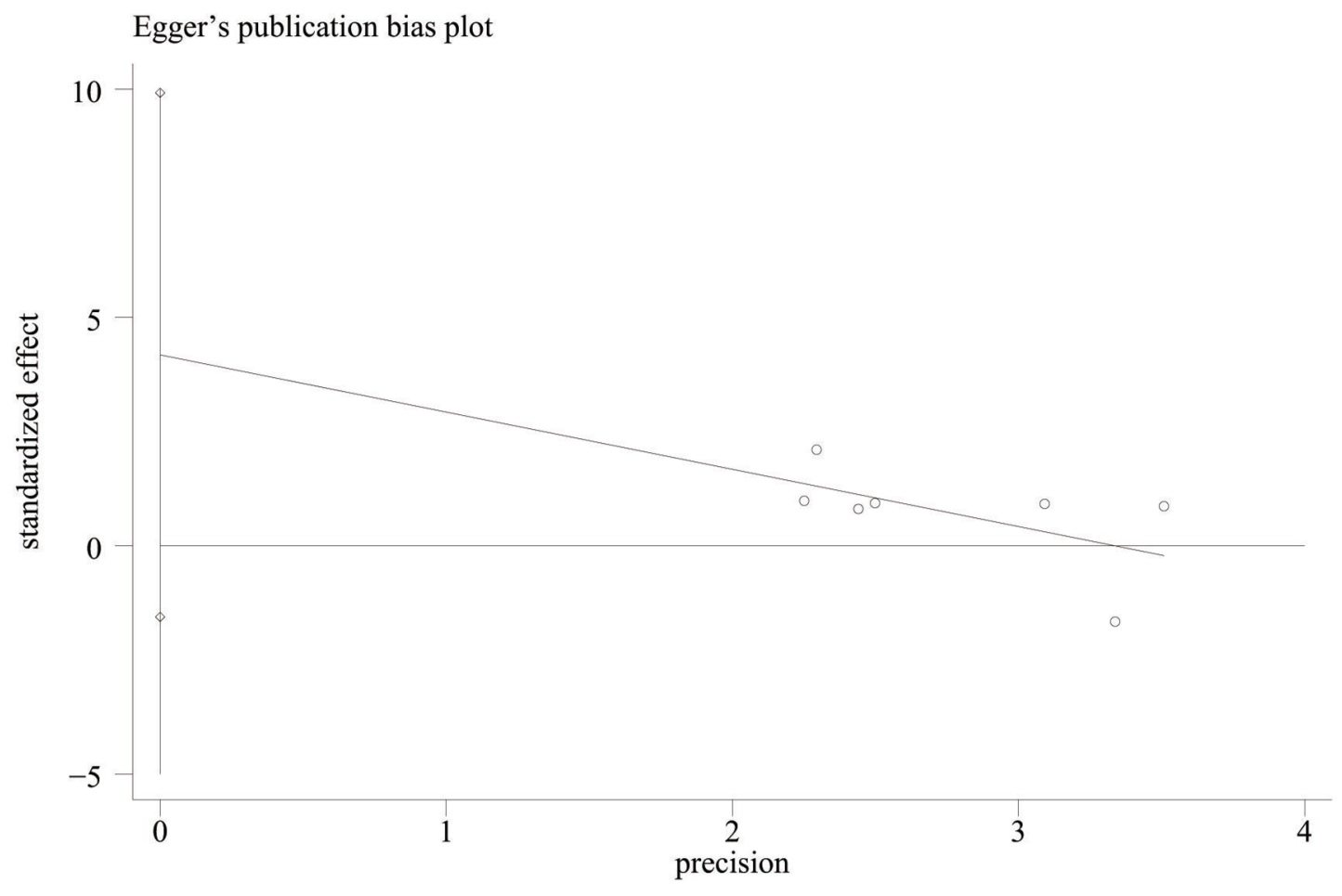

Figure 4: Funnel plot of publication bias for the co-dominant model (GG $v s$ TT) in the meta-analysis with Egger's test. 


\section{DISCUSSION}

Prostate cancer is a serious cancer that affects a large number of patients. As a multi-factor disease, genetic mutation has been found to play a key role in its development and progression. Recently, the APEX1 Asp148Glu (rs1130409) polymorphism was found to be associated with Pca risk [30]. However, this conclusion was controversial. In 2014, Li et al. investigated the association between rs 1130409 and Pca [32]. Then, based on the same data, a new meta-analysis was conducted, which had discovered the other association in special ways [31]. Although the two meta-analyses focused on the association between APE1 polymorphisms and Pca in two aspects, our study was conducted in a different way to investigate the potential relationship more comprehensively. First, we updated the meta-analysis with studies from various databases (PubMed, Embase, HuGENet and CNKI); one additional study conducted by Pournourali et al. [30] was included. Secondly, in our meta-analysis, the ethnicities of the subjects were divided into three parts (Asian descent, mixed descent and African descent ) in order to understand the association between APEX1 polymorphisms and Pca more in more detail in different populations. After the analysis, a potential relationship was found among the mixed descent subjects (a mix of European descent, African descent, and others) and subjects of Asian descent, which had not been reported in the previous studies [31-32]. In addition, we also conducted an additional valuable analysis, which was mainly focused on the function of the APE1 polymorphism in the development of Pca. In this part of the study, the Gleason score, prostate-specific antigen expression and clinical status of the cancer were included to evaluable the status of Pca. Although we did not obtain any positive results, this result suggests that rs1130409 might be a hereditary factor associated with Pca that promotes the development rather than the invasion of Pca to some extent.

APEX1 is an important gene encoding for DNA (apurinic or apyrimidinic site) lyase, which belongs to the BER pathway activating DNA repair, the cell

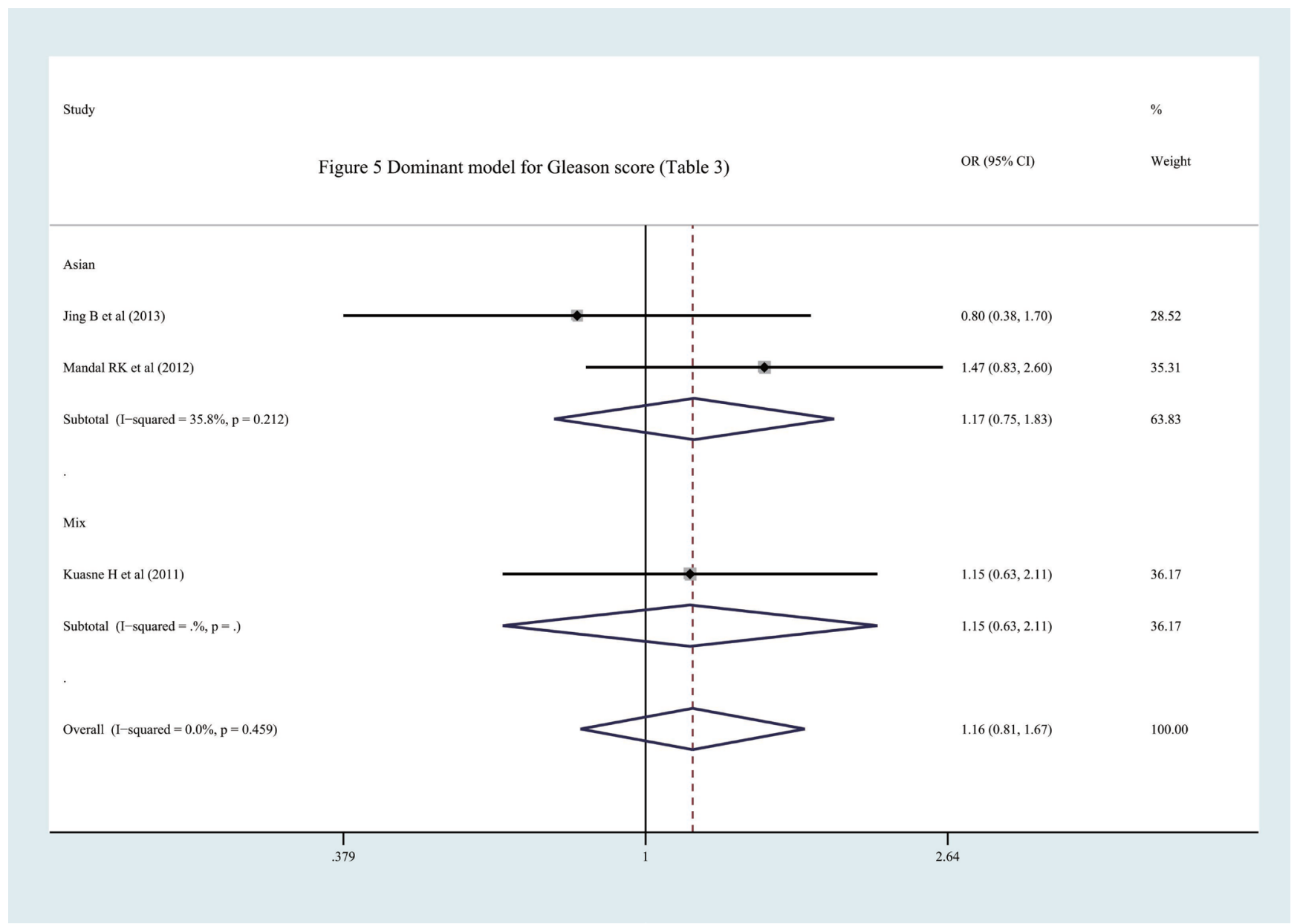

Figure 5: Meta-analysis with fixed effects and Dominant model (GG+GT $v s$ TT) for the association between APEX1 Asp148Glu polymorphism and the prostate cancer risk (Gleason score \{Greater than or equal to\} 7) with three studies. The first author and year of publication for each study was shown. In this analysis, three subgroups were shown: China, India and Mixed. OR and accompanying 95\% CI were presneted for this association. 
cycle, and apoptosis $[9-10,12]$. As the most frequently assessed variant, the APEX1 Asp148Glu polymorphism is thought to be associated with many cancers [14$16,23-25,27]$. As for its biological function, APEX1 is related to a greater sensitivity to ionizing radiation, thus inducing mitotic delay in lymphocytes [33]. In order to describe the characteristics of this locus, we performed TagSNP, linkage disequilibrium (LD) and SNP function analysis with Haploview 4.2 and SNP Function Prediction (FuncPred) (http://manticore.niehs.nih.gov/ snpinfo/snpfunc.htm), which suggested that the APEX1 Asp148Glu polymorphism is a tag- and functional SNP in the LD block with other SNPs in the APEX1 gene. In addition, as a missense mutation, we have reason to believe that the APEX1 Asp148Glu polymorphism is an important locus to study.

In 2013, Mahjabeen et al. [23] showed that APEX1 mutations and the deregulation of APEX1 are associated with an increased risk of head and neck cancer in the Pakistani population. Meanwhile, Li et al. [24] identified that polymorphisms of the APEX1 gene might contribute to tumorigenesis in lung cancer among the Chinese population. In addition, the APEX1 gene could also increase the risk of glioblastoma [25], gastric cancer [26], and bladder cancer [27]. Recently, more studies have shown that the APEX1 gene plays a key role in the development and progression of Pca. In 2001, Kelley et al. [28] studied the function of the Ape1/ ref-1 enzyme in the risk of Pca, which suggested that this enzyme might be a diagnostic marker for early Pca and play a role in the physiology of the early development of this disease. As one of the important polymorphisms of APEX1 gene, rs1130409 has been suspected to be significantly associated with Pca. In 2006, Chen et al. [17] first studied the relationship between the APEX1 Asp148Glu polymorphism and Pca in white and black Americans, and identified the positive function of this polymorphism in determining the risk of Pca. Then, in 2011, Kuasne et al. [22] confirmed this significant association again in Brazilian men. However, there were no publically available GWAS databases, and GWAS analysis had evaluated this SNP and Pca outcomes before. Recently, two meta-analyses were conducted that showed a significant association between the APEX1 Asp148Glu polymorphism and Pca, especially among Caucasian subjects and the hospital-based population [31-32]. In order to discover the real association, this analysis was conducted. Although a positive association between the APEX1 Asp148Glu polymorphism and Pca was presented in the pooled and special subgroups analysis (mixed and Asian descent), after considering the HWE, the significant association was disappeared among all pooled and mixed descents. In order to confirm these associations, a sensitivity analysis was performed by removing the studies one by one, which suggested that the APEX1 Asp148Glu polymorphism should be associated with
Pca, especially in subjects of Asian descent. In addition, we directed our attention to the invasion of Pca. After a comprehensive analysis, we could not identify an explicit relationship. So, on the basis of this analysis, we suggest that the APEX1 Asp148Glu polymorphism might be more important in the development of Pca rather than invasion. In order to confirm these results, the Gene Expression Omnibus (GEO) (https://www.ncbi.nlm.nih.gov/geo/) was applied, in which GSE76470 was used. GSE76470 is mainly focused on the differences in gene expression between epithelial-like (EL) clones with high tumorigenic ability. In other words, EL clones appear to be more aggressive compared to mesenchymal-like (ML) Pca cells. After analysis, we found that there was no statistical difference between aggressive and non-aggressive Pca regarding APEX1 gene expression (adjusted $P$-value $=0.87091, \log \mathrm{FC}=0.07395)$, which might explain the reason for the lack of an association between the APEX1 Asp148Glu polymorphism and invasive Pca to some extent.

Combining the features and function of the APEX1 Asp148Glu polymorphism, recent studies and our comprehensive analysis, we suggest that the rs1130409 mutation might increase the risk of developing Pca, especially among Asian subjects.

\section{LIMITATIONS}

After a comprehensive meta-analysis, a relationship between Pca and the APEX1 Asp148Glu polymorphism was shown. However, there are still some limitations. Firstly, the number of studies on the association between the APEX1 Asp148Glu polymorphism and Pca is limited. We cannot rule out a significant relationship between SNP and Pca outcomes, which may be attributed to the lack of statistical power to observe significant relationships to some extent. Secondly, the populations in the studies were different, especially regarding the mixed race subgroup, which could result in some heterogeneity in the results. Thirdly, there were three polymerase chain reaction (PCR) methods applied, namely PCR-restriction fragment length polymorphism (PCR-RFLP) analysis, amplification refractory mutation specific PCR (ARMS-PCR) analysis and TaqMan-PCR. The genotype misclassification for each method might affect the risk estimates in some way. Finally, research into the mechanism of the APEX1 Asp148Glu polymorphism in the development and progression of Pca was limited, especially regarding interactions with other BER pathway genes and the environment.

\section{CONCLUSIONS}

Prostate cancer is a cancer of global concern. The APEX1 Asp148Glu polymorphism is thought to be associated with Pca risk; this study was conducted in 
order to make this relationship clearer. Our results suggest that the APEX1 Asp148Glu polymorphism is significantly associated with Pca in subjects of Asian descent as well as in other populations, and might stimulate the development of Pca rather than invasion. Additional larger and ethnically diverse studies are needed to confirm the real relationships and functions.

\section{MATERIALS AND METHODS}

\section{Searching and collecting}

Our eligible studies were mainly retrieved from the PubMed, Embase, HuGENet and Chinese National Knowledge Infrastructure (CNKI) databases. In order to collect more comprehensive eligible studies, we conducted an extensive retrieval, with the following keywords combined: "apurinic/apyrimidinic endonuclease", "APE1", “APEX1”, "APEN”, "HAP1”, "Pca”, "prostate cancer”, "prostatic carcinoma", and "prostate carcinoma". All studies identified were original research articles and were written in English or Chinese. The last search was performed in October 2015. In order to select the eligible studies, we set the following inclusion criteria: (1) the essential contents were about the APEX1 Asp148Glu polymorphism and Pca; (2) studies were designed in casecontrol or cohort format, which could distinguish the case group and controls; (3) the number of cases and controls for separate genotypes should be provided. In other words, sufficient information for estimating the OR and the 95\% CI should be provided.

After selecting the included studies, we summarized the population characteristics of all seven studies for our meta-analysis, including the author's name, publication year, country, ethnicity (categorized as Asian descent, African descent or mixed descent ), definition of cases and controls, allelic discrimination method, and numbers of cases and controls, as shown in Table 1.

\section{Statistical analysis}

Frequencies of every genotype were included in the next analysis. In order to describe the association between the APEX1 Asp148Glu polymorphism and Pca risk, we selected four common genotype models, including the dominant $(\mathrm{GG}+\mathrm{GT}$ versus $\mathrm{TT})$, recessive (GG versus $\mathrm{GT}+\mathrm{TT}$ ), co-dominant model (GG versus GT; GG versus $\mathrm{TT}$ ) and per-allele analysis (A versus $\mathrm{C}$ ). As for the effect model, $I^{2}$ was treated as standard (when $I^{2}<$ $50 \%$, the fixed effect was applied; otherwise, the random effect would be selected). The effects incorporated an estimate of the inter-study variance and provided wider $95 \%$ confidence intervals $(95 \% \mathrm{CI})$ if the results of the constituent studies differed among themselves. In all the analyses, the relationship between the APEX1 Asp148Glu SNP and Pca were estimated using odds ratios and the corresponding 95\%CI. The current study estimated both population-specific and pooled risk estimates. Meanwhile, the chi-squared-based Q statistic $(P<0.10$ as the standard) was applied to estimate heterogeneity, which represented the weighted sum of the squared difference in the overall effect sizes from each study [18]. Then, we conducted the subgroup analysis by collecting similar characteristics form the eligible studies, such as country of origin and ethnicity. In this meta-analysis, five countries were represented: China, India, Iran, Brazil and America. As for the races, three groups were represented: Asian descent, African descent and mixed descents . Then, the HardyWeinberg equilibrium (HWE) for each study was taken into consideration. This process of analysis was conducted after removing studies that did not satisfy HWE to confirm our results.

Meanwhile, in order to understand the function of the APEX1 Asp148Glu polymorphism in Pca development, a further analysis was conducted. In this part of the study, three indexes [Gleason score (GS), clinical status and the level of prostate-specific antigen (PSA)] were considered. After re-reading the included studies, three of them were found to contain the necessary data and were analyzed $[8,20,22]$. For GS and PSA, two groups were generated based on the threshold of 7 (GS case: GS $\geq 7$, GS control: GS $<7$ ) and 10 (PSA case: PSA $>10 \mathrm{ng} / \mathrm{mL}$, PSA control: PSA $\leq 10 \mathrm{ng} / \mathrm{mL}$ ), respectively. In addition, according to the invasiveness of the cancer, another two groups were also defined (case: advanced or metastasis $(+)$ or clinical stage $\geq \mathrm{T} 3$; control: localized or metastasis (-) or clinical stage $<$ T3).

Publication bias was evaluated with Egger's linear regression test and a funnel plot. The statistical power was calculated with Power and Precision V4 software (http:// www.power-analysis.com/). All $P$ values were two-tailed, and data were analyzed using Stata 9.0 (Stata Corporation, USA).

\section{ACKNOWLEDGMENTS}

This study was funded by Guangxi Natural Science Fund for Innovation Research Team(2013GXNSFFA019002), Guangxi Collaborative Innovation Center for genomic and personalized medicine(201319), Program for New Century Excellent Talents in University (NCET-12-0653), Guangxi Natural Science Fund for Distinguished Young Scholars (2012jjFA40011), The Science and technology development plan of Guangxi (Guikegong 1355005-3-17), National Program on Key Basic Research Project (973 Program) (2012CB518303), Natural Science Foundation of China (81460388). 


\section{CONFLICTS OF INTEREST}

There is no conflict of interest.

\section{REFERENCES}

1. Siegel R, Ma J, Zou Z, Jemal A. Cancer statistics, 2014. CA Cancer J Clin. 2014;64:9-29. [PubMed: 24399786].

2. Siegel RL, Miller KD, Jemal A. Cancer statistics, 2015. CA Cancer J Clin. 2015;65:5-29. [PubMed: 25559415].

3. Siegel RL, Fedewa SA, Miller KD, Goding-Sauer A, Pinheiro PS, Martinez-Tyson D, Jemal A. Cancer statistics for Hispanics/Latinos, 2015. CA Cancer J Clin. 2015;65:457-80. [PubMed: 26375877].

4. Siegel RL, Miller KD, Jemal A. Cancer statistics, 2016. CA Cancer J Clin. 2016;66:7-30. [PubMed: 26742998].

5. Chen W, Zheng R, Baade PD, Zhang S, Zeng H, Bray F, Jemal A, Yu XQ, He J. Cancer statistics in China, 2015. CA Cancer J Clin. 2016;66:115-32. [PubMed: 26808342].

6. Bostwick DG, Burke HB, Djakiew D, Euling S, Ho SM, Landolph J, Morrison H, Sonawane B, Shifflett T, Waters DJ, Timms B. Human prostate cancer risk factors. Cancer. 2004;101:2371-490. [PubMed: 15495199].

7. Chen Y, Li T, Yu X, Xu J, Li J, Luo D, Mo Z, Hu Y. The $\mathrm{RTK} / \mathrm{ERK}$ pathway is associated with prostate cancer risk on the SNP level: a pooled analysis of 41 sets of data from case-control studies. Gene. 2014;534:286-97. [PubMed: 24177231].

8. Jing B, Wang J, Chang WL, Li B, Chen J, Niu YJ. Association of the polymorphism of APE1 gene with the risk of prostate cancer in Chinese Han population. Clin Lab. 2013;59:163-8. [PubMed: 23505922].

9. Hung RJ, Hall J, Brennan P, Boffetta P. Genetic polymorphisms in the base excision repair pathway and cancer risk: a HuGE review. Am J Epidemiol. 2005;162:925-42. [PubMed: 16221808].

10. Ide H, Kotera M. Human DNA glycosylases involved in the repair of oxidatively damaged DNA. Biol Pharm Bull. 2004;27: 480-5. [PubMed: 15056851].

11. Demple B, Harrison L. Repair of oxidative damage to DNA: enzymology and biology. Annu Rev Biochem. 1994;63:915-48. [PubMed: 7979257].

12. Evans AR, Limp-Foster M, Kelley MR. Going APE over ref-1. Mutat Res. 2000;461:83-108. [PubMed: 11018583].

13. Pan H, Niu W, He L, Wang B, Cao J, Zhao F, Liu Y, Li S, $\mathrm{Wu} \mathrm{H}$. Contributory role of five common polymorphisms of RAGE and APE1 genes in lung cancer among Han Chinese. PLoS One. 2013;8:e69018. [PubMed: 23874853].

14. Wang $M$, Chu H, Wang S, Wang M, Wang W, Han $\mathrm{S}$, Zhang Z. Genetic variant in APE1 gene promoter contributes to cervical cancer risk. Am J Obstet Gynecol. 2013;209:360.e1-7. [PubMed: 23871947].

15. Zhang X, Xin X, Zhang J, Li J, Chen B, Zou W. Apurinic/ apyrimidinic endonuclease 1 polymorphisms are associated with ovarian cancer susceptibility in a Chinese population. Int J Gynecol Cancer. 2013;23:1393-9. [PubMed: 24257553].

16. Li Y, Li S, Wu Z, Hu F, Zhu L, Zhao X, Cui B, Dong X, Tian S, Wang F, Zhao Y. Polymorphisms in genes of APE1, PARP1, and XRCC1: risk and prognosis of colorectal cancer in a northeast Chinese population. Med Oncol. 2013;30:505. [PubMed: 23430444].

17. Chen L, Ambrosone CB, Lee J, Sellers TA, Pow-Sang J, Park JY. Association between polymorphisms in the DNA repair genes XRCC1 and $\mathrm{APE} 1$, and the risk of prostate cancer in white and black Americans. J Urol. 2006;175:10812; discussion 112. [PubMed: 16406883].

18. Lau J, Ioannidis JP, Schmid CH. Quantitative synthesis in systematic reviews. Ann Intern Med. 1997;127:820-6. [PubMed: 9382404].

19. Agalliu I, Kwon EM, Salinas CA, Koopmeiners JS, Ostrander EA, Stanford JL. Genetic variation in DNA repair genes and prostate cancer risk: results from a populationbased study. Cancer Causes Control. 2010;21:289-300. [PubMed: 19902366].

20. Mandal RK, Gangwar R, Kapoor R, Mittal RD. Polymorphisms in base-excision \&amp; nucleotide-excision repair genes \&amp; prostate cancer risk in north Indian population. Indian J Med Res. 2012;135:64-71. [PubMed: 22382185].

21. Mittal RD, Mandal RK, Gangwar R. Base excision repair pathway genes polymorphism in prostate and bladder cancer risk in North Indian population. Mech Ageing Dev. 2012;133:127-32. [PubMed: 22019847].

22. Kuasne H, Rodrigues IS, Losi-Guembarovski R, Reis MB, Fuganti PE, Gregório EP, Libos Junior F, Matsuda HM, Rodrigues MA, Kishima MO, Cólus IM. Base excision repair genes XRCC1 and APEX1 and the risk for prostate cancer. Mol Biol Rep. 2011;38:1585-91. [PubMed: 20852942].

23. Mahjabeen I, Baig RM, Sabir M, Kayani MA. Genetic and expressional variations of APEX1 are associated with increased risk of head and neck cancer. Mutagenesis. 2013;28:213-8. [PubMed: 23408843].

24. Li Z, Guan W, Li MX, Zhong ZY, Qian CY, Yang XQ, Liao L, Li ZP, Wang D. Genetic polymorphism of DNA base-excision repair genes (APE1, OGG1 and XRCC1) and their correlation with risk of lung cancer in a Chinese population. Arch Med Res. 2011;42:226-34. [PubMed: 21722819].

25. Zhou K, Hu D, Lu J, Fan W, Liu H, Chen H, Chen G, Wei Q, Du G, Mao Y, Lu D, Zhou L. A genetic variant in the APE1/Ref-1 gene promoter -141T/G may modulate risk of glioblastoma in a Chinese Han population. BMC Cancer. 2011;11:104. [PubMed: 21429202].

26. Canbay E, Agachan B, Gulluoglu M, Isbir T, Balik E, Yamaner S, Bulut T, Cacina C, Eraltan IY, Yilmaz A, Bugra D. Possible associations of APE1 polymorphism with 
susceptibility and HOGG1 polymorphism with prognosis in gastric cancer. Anticancer Res. 2010;30:1359-64. [PubMed: 20530453].

27. Narter KF, Ergen A, Agaçhan B, Görmüs U, Timirci O, Isbir T. Bladder cancer and polymorphisms of DNA repair genes (XRCC1, XRCC3, XPD, XPG, APE1, hOGG1). Anticancer Res. 2009;29:1389-93. [PubMed: 19414392].

28. Kelley MR, Cheng L, Foster R, Tritt R, Jiang J, Broshears $\mathrm{J}$, Koch M. Elevated and altered expression of the multifunctional DNA base excision repair and redox enzyme Ape1/ref-1 in prostate cancer. Clin Cancer Res. 2001;7:824-30. [PubMed: 11309329].

29. Lavender NA, Komolafe OO, Benford M, Brock G, Moore JH, Vancleave TT, States JC, Kittles RA, Kidd LC. No association between variant DNA repair genes and prostate cancer risk among men of African descent. Prostate. 2010 ;70:113-9. [PubMed: 19760636].
30. Pournourali M, Tarang AR, Yousefi M. The association between 1349T $>\mathrm{G}$ polymorphism of ApE1 gene and the risk of prostate cancer in northern Iran. Cell Mol Biol (Noisy-le-grand). 2015;61:21-4. [PubMed: 26255264].

31. Zhou X, Wei L, Jiao G, Gao W, Ying M, Wang N, Wang Y, Liu C. The association between the APE1 Asp148Glu polymorphism and prostate cancer susceptibility: a meta-analysis based on case-control studies. Mol Genet Genomics. 2015;290:281-8. [PubMed: 25234162].

32. Li X, Zhang G, Huai YJ, Cao ZQ. Association between APE1 T1349G polymorphism and prostate cancer risk: evidence from a meta-analysis. Tumour Biol. 2014;35:10111-9. [PubMed: 25023401].

33. Hu JJ, Smith TR, Miller MS, Mohrenweiser HW, Golden A, Case LD. Amino acid substitution variants of APE1 and $\mathrm{XRCC} 1$ genes associated with ionizing radiation sensitivity. Carcinogenesis. 2001;22:917-22. [PubMed: 11375899]. 